\title{
Aves de arribação: a migração dos intelectuais
}

A José Arthur Giannotti, que não arribou.

Francisco de Oliveira*

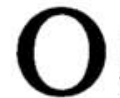

período autoritário parecia ter despertado uma intensa atividade intelectual no país. Dirse-ia, à moda do método antigo de apressar o amadurecimento de frutos, que o regime autoritário funcionou como uma espécie de carbureto, forçando os diversos ramos técnico-científicos a ingressarem na maturidade. As reuniőes da SBPC transformaram-se num foro importantíssimo, dando-se as mãos intelectuais dos mais diversos ramos na discussão de questðes magnas do próprio conhecimento, da cultura, da economia e da sociedade brasileira. Nas ciências humanas, as últimas a adquirirem o status científico, as associações de pesquisa instalaram-se e floresceram, seguindo os passos de suas congêneres dos ramos chamados "exatos". (Aqui e ali irromperam atitudes com intençð̃es - menos que possibilidades concretas - de uma física "nacio- nal", uma tecnologia "nacional", minicentrais elétricas "comunitárias", biologia não apenas de massas mas das massas, elogio do trabalho "informal"). Ironia à parte, é fato que no meio de uma produção de "protesto", momentos de qualidade acadêmica indiscutível não foram raros. Visitantes de outros países se impressionaram com o vigor das reuniões da SBPC, únicas em todo o mundo.

Talvez $o$ amadurecimento tenha sido mesmo no carbureto e nunca tenha passado de uma produção de "protesto"; ou os intelectuais, mestres da ilusão, confundiram prestidigitação com o real; pode ser que a comparação com períodos anteriores levasse a superestimar a produção corrente; ou se trata de fenômeno mais complexo e mais grave, que tefn a ver com a nova posição do intelectual na estrutura social, suas relaçð̃es com as outras classes, com a produção de mercadorias (inclusive a cultural), com a política e finalmente com o Estado. Pois o fato é que os intelectuais estão abandonando suas pesquisas, suas salas de aula, seus laboratórios, para transformarem-se em 
gestores do poder: migrando para 0 controle da burocracia da pesquisa, para postos governamentais nos níveis federal e estadual. Mais: a arma da crítica foi sendo gradualmente posta de lado, substituída por uma subliteratura apologética, justificada pelo papel do intelectual na construção da democracia e pelos riscos a que essa "novidade" está sujeita.

O nível da crítica na produção de hoje é baixíssimo: predominam os debates nas "margens" dos problemas. Em economia, é a taxa de juros, o controle do déficit público, a dívida externa e a inflação; desapareceram os problemas que toda uma escola de pensamento chamou "estruturais". $\mathrm{Na}$ ciência política, a reconstrução de processos decisórios, como se o passado pudesse prescrever o presente e 0 futuro; 0 desencontro do "país real" com o "país legal", como se esse desencontro não fosse mais que o descompasso entre "conteúdo" $e$ "forma". Na sociologia, o pastiche da antropologia, atual "rainha" das ciências humanas; uma antropologização que é recusa de tratar dos temas críticos, em vez de, como na ciência "rainha", ser rigor de método. Em geral, uma mal disfarçada ojeriza ao marxismo, em nome do combate à vulgata, mas que, no fundo, traduz a incapacidade ou a opção de não tomar partido, posto que o marxismo requer, como exigência intrinseca do método, tomar partido; como resultado geral, a emergência de um neoliberalismo teórico, justificado pelo pluralismo da sociedade capitalista contemporânea; este não é pensado comó sín- tese, mas, simplesmente, como soma. A prática dos cientistas - que aparece com maior clareza nas ciências humanas, mas não está ausente das "exatas" - tornou-se conciliadora, do tipo " "não faz onda para a gente não se afogar", justificadora do novo regime político, prestidigitando outra vez, posto que a dinâmica das estruturas básicas da sociedade e do Estado continua a mesma, mas transita-se para a democracia sem amarraçóes com o real. Levitase, na verdade, e a verdade levita... Tudo deve ser compreendido nos marcos de uma "transição", que nunca é definida, nem se sabe em que direção vai, nem a quem serve. A nova democracia, diriam, com o auxílio de poetas menores do parnasianismo brasileiro, "é uma plantinha frágil que requer muitos cuidados"...

\section{Não há uma \\ correlação mecânica}

Convém, para examinar a questão, descartar desde logo qualquer correlação mecânica entre opressão política e vigor da produção intelectual; além disso, impóe-se uma avaliação mais séria do que se produziu nos anos do regime autoritário. Mas os pontos verdadeiramente nevrálgicos residem, em primeiro lugar, no exame das relaçð̃es entre a produção científica, a chamada "comunidade científica", e os regimes políticos e, em segundo lugar, na indagação sobre a posição dos cientistas e intelectuais na estrutura social, suas relações com as demais classes, e suas relaçôes com a polí- 
tica e o Estado. Convém tanto escapar do clichê autoglorificador do cientista perseguido e incompreendido, do cientista "por definição" de oposição, e da ciência como a razão em busca do bem comum, quanto da indeterminação de classe do intelectual, de seu desapego "franciscano", de seu despojamento de interesses materiais. Se o reducionismo de que a produção científica é determinada pela classe social a que pertencem os intelectuais pode ser estreito, o outro extremo de que o cientista paira acima das classes sociais é mistificar: às vezes, a produção intelectual "não tem classe científica", o que é outra história.

Como primeiro ponto a resgatar é preciso estabelecer as relações entre a produção científica e economia. No capitalismo contemporâneo, onde as ciências comparecem como elementos constitutivos das forças produtivas, não há expansão econômica sem desenvolvimento científico. E, no caso brasileiro, houve uma enorme expansão no período autoritário. É certo que a condição de não-produtor de tecnologia atenua o papel da produção científica na acumulação de capital, mas não a anula completamente. Mesmo para copiar tecnologia de outras economias mais avançadas, requer-se conhecimento científico. $O$ grande empuxo da produção científica no Brasil deve-se, em primeiro lugar, à expansão ocorrida, e não aos cientistas. A relação entre o regime político e a produção científica é mais complexa, mas sua primeira determinação encontra-se naquele nível de desenvolvimento das forças produtivas. $\mathrm{O}$ regime autoritário atuou conscientemente no sentido de elevar o nível da produção científica, em alguns ramos, não em todos. A criação da FINEP, por exemplo, dá mostras disso. A ampliação dos laboratórios de física em algumas principais universidades também 0 atesta. A criação da indústria da informática, bafejada, financiada e tendo por mercado cativo a indústria bélica e outros setores estatais, também o confirma. Nesse ambiente, a possibilidade de ocórrerem oposiçðes técnicas entre cientistas e o regime político é tão certa como o fato de que não há, nunca, uma única opção, mas várias. A oposição da maioria dos físicos ao programa nuclear não era uma oposição ao programa nuclear, mas à opção que o regime fez pela tecnologia alemã. Uma oposição "ecologista-pacifista" quase não existiu.

\section{O "milagre" e}

\section{as ciências humanas}

Já as relações entre economia, regimes políticos e ciências humanas são muito mais complexas. Em geral, também as ciências humanas se aproveitam do ambiente de expansão econômica. Os intelectuais brasileiros tiveram acesso à produção internacional, circularam nos congressos internacionais - uns forçados pelo exílio, outros devido a antigas relaçōes, outros ainda $f i$ nanciados pelo Estado. Em uma situação de estagnação econômica, isto não poderia ter sido feito, haja vista o que se passa com as ciências 
humanas em outros países da América Latina, como Paraguai, Bolívia, Haiti e quase todos da América Central. Permanece a interrogação sobre a relação com o regime autoritário. É certo que os regimes desse tipo têm horror às ciências sociais ou humanas. Mesmo nos casos de antiga e forte tradição intelectual, como na Alemanha e Itália, o horror do regime às ciências humanas foi decisivo para retardar a ampliação delas naqueles países, com o que o eixo da hegemonia intelectual em vários ramos, na ciência política e na economia como na sociologia, deslocou-se para os Estados Unidos. No Brasil, o regime autoritário combateu ferozmente as' ciências humanas e seus intelectuais portadores, mas deixou - pelo menos que se ampliassem os cursos universitários de ciências humanas em todas as partes do país. Com o que os cientistas sociais tiveram ampliado o mercado de suas idéias, pesquisas e livros. $\mathrm{O}$ mercado não é suficiente para explicar: falta pôr o acento na relação que os cientistas sociais começaram a desenvolver com a sociedade menos que com o Estado. Foi daí que veio o impulso decisivo.

A expansão capitalista aguardou os intelectuais na curva. Pois, na estrutura social contemporânea, os intelectuais são, decisivamente, membros das classes médias afluentes. Cresceram em número, tiveram seus salários e rendas aumentados muito mais que a média dos trabalhadores (e a relativa erosão dos últimos anos serviu tão-somente para jogá-los ainda mais na oposição ao regime, mas não ao_sistema capitalista), subiram de status, escrevem nos principais jornais, são considerados "oráculos" do que se passa, principalmente os economistas. Pelo consumo e pelo modo de vida, aproximaram-se das burguesias, e até as superam em certos maneirismos, pois são mais requintados, não viajam em excursð̃es, distinguem o bom vinho francês do "beaujolais nouveau", falam outras linguas, têm algum conhecimento da eultura de outros povos, o que lhes dispensa os guias turísticos para reconhecer a Tour Eiffel, e sabem de antemão que o Taj Mahal foi construído por um rajá desolado em memória de sua bem-amada esposa. Não se atropelam nas lojas chiques da Rue de Rivoli ou da Fifth Avenue, e compram os últimos badulaques da eletrônica japonesa discretamente, discretamente...

\section{Núcleo importante} das classes médias

Tornaram-se, pois, solidários com o êxito do sistema capitalista no Brasil. Neste, desempenham um papel central; além de outras razð̃es, constituem o núcleo mais importante das classes médias, cuja centralidade no capitalismo de hoje deslocou a antiga centralidade operária. Converteram-se em atores privilegiados da mídia política, e elevam suas demandas específicas ao nível de demandas gerais da sociedade. Por esse complexo de razões, se des-solidarizam com o destino das classes sociais dominadas. Objetivamente, pela trama de relações tecidas no interior dos pactos burocrá- 
ticos estatal e civil, seu destino de classe parece não ter ligação com o das classes sociais dominadas, pois os salários dos cientistas e intelectuais não têm por parâmetro a utilidade de sua força de trabalho para o capital, mas os fundos públicos. Subjetivamente, modernos narcisos, seu processo de reconhecimento, sua alteridade, não se dá na relação com o outro, mas consigo mesmo: miram-se no espelho, cotidianamente, e esse espelho é formado pela opinião que os outros demandam dos intelectuais sobre qualquer coisa que passe no ar, inclusive os aviőes de carreira...

\section{Só quem controla}

\section{a mídia política}

O período autoritário operou um amálgama de amplas forças sociais divergentes entre si mas convergentes no repúdio a ele. É na opção de metamorfose de forças sociais em forças políticas que se dá a disjunção da anterior coligação de forças. Pois essa metamorfose se dá pela via da institucionalização de formas de representação da democracia burguesa, formas que não são coetâneas da dispersão de identidade que a sociedade de massas produz. Este processo assincrônico e assimétrico não traduz a sociedade de classes em sociedade política, e permite que a formalização institucional seja alcançada apenas pelos grupos que têm controle sobre a mídia política. Em si mesmo, este processo é parcialmente responsável pelo "balaio de gatos" dos partidos políticos. No que respeita à intelectualidade, esse processo lhe é particularmente favorável, pois estão instalados no coração da mídia política. A rigor, não se trata de representação, mas de apresentação, a qual é reiterada cotidianamente porque é cotidianamente fugaz, mas qualquer processo político requer, como mínimo, alguma efetividade e alguma eficácia. E neste momento comparece o outro atributo da intelectualidade: ela é o "elo perdido" entre a reiteração e a fugacidade, o articulador de um universal abstrato que é o discurso da eficácia. Como agente "técnico", a intelectualidade produz um discurso inespecífico, funcional para a mídia, que apresenta ligar o que é fragmentado.

O novo regime político chamado "Nova República" é o momento daquela disjunção. Abalado nos seus alicerces o regime autoritário, a metamorfose das forças sociais em forças políticas obedeceu ao padrão combinado de institucionalidade formal mais controle da mídia política; as forças sociais mais antagônicas ao regime, que imprimiram o formidável empuxo da campanha da anistia e depois das diretas-já, foram escanteadas para fora do espectro político. A frente que se formou, com o PFL e PMDB, combinou os elementos de institucionalização e controle da mídia política para alçar-se ao primeiro plano da nova institucionalidade, relegando as forças sociais que não alcançaram completar a metamorfose para forças políticas a um remoto e relegado segundo plano - ainda que algumas delas estejam, parcialmente, tentando completar aquele processo. Aqui, então, comparece 
o peso dos intelectuais: essa metamorfose exige alguma eficácia, para forjar uma representação de interesses que são apenas apresentados: o papel dos intelectuais nas estruturas burocráticas do Estado e da empresa é decisivo para tanto.

\section{Começa a migração}

A partir daí, começou a migração das aves de arribação intelectuais para o poder, os aparelhos de Estado. Inclusive os que cuidam da pesquisa, do ensino, da cultura, da ciência e da tecnologia. A Nova República os convoca para aquilo a que foram treinados, e mais: para aquilo que apenas eles são capazes de fazer, isto é, dar a impressão de universalidade a fugacidade de que se constitui a midia, e é aquela impressão de universalidade que constitui a eficácia. Pois operários somente falarão de salários, enquanto empresários apenas falarão de lucros: os intelectuais falam do universal não-concreto que é $a$ dívida externa, $a$ inflação, $a$ dívida interna, $a$ política, $a$ cultura. Esta universalização não-concreta é o segredo da decadência da produção crítica, pois jamais se refere a processos concretos mediante os quais se constitui o universal concreto, mas processos universais que remetem a concretos indiferenciados e, pois, não-concretos.

As consequências para a produção científica e intelectual não são nada alvissareiras. A atitude e a situação conservadora dos intelectuais preparam o caminho para uma produção conservadora: já está todos os dias nos jornais. A "ciência normal" e seus paradigmas serão predominantes; mesmo a irrupção de fortes personalidades, com obra original e subversiva, será atenuada pelo controle da mídia política. Todos os ramos científicos serão chamados a "aplicar" seus conhecimentos, desde as "exatas" - na tarefa de dar sustentação à acumulação de capital mediante a aplicação tecnológica - até as humanas, na tarefa de "sanear" as finanças, compatibilizar o que é incompativel, achar os caminhos da cooptação dos movimentos sociais pelo Estado, administrar os conflitos trabalhistas, confirmar sociologicamente a perda de identidade na sociedade de massas, justificar a não tradução em sociedade política de uma sociedade estruturada conflitivamente em classes, proclamar o desuso da luta de classes. Se os intelectuais foram, no passado populista, vanguarda de uma burguesia retardatária, tendem a ser, no presente e no futuro próximo, mera retaguarda da justificação ideológica da hegemonia burguesa. Ainda que o efeito da mídia os apresente como oráculos, a rigor eles são uma espécie de profetas do acontecido. Perderam ou tendem a perder seu papel subversivo na sociedade.

Do ponto de vista política, o conservadorismo dos intelectuais tende a ser desastroso. Se, na maior parte dos casos, a posiçāo conservadora é justificada em nome de não ameaçar o crescimento da "plantinha frágil" da nova democracia, na verdade com semelhante posição os intelectuais estão conspirando seriamente para a inviabilidade da de- 
mocracia no Brasil. Pois des-alimentam a tensão entre presente $\mathrm{e}$ futuro, entre realidade e utopia, entre status quo e sua superação. Quem quer que se dê ao trabalho de leitura da produção, mesmo jornalística, dos mais ativos intelectuais brasileiros do momento, não encontrará a menor referência às questões do sistema econômico, social e político. O socialismo, por exemplo, foi mandado à região das sombras, o que se deve não tanto ao descrédito do chamado "socialismo real", mas à recusa em aceitar o desafio de pensar-se uma nova totalização que não passe pela idéia de comunistas (do que decorre, em parte, o declínio dos partidos comunistas e a dificuldade do PT, o último partido “comunista", em implantar-se na sociedade brasileira); essa recusa implica a aceitação da barbárie moderna que é o pluralismo de ilhotas, base do neoliberalismo. O risco do futuro, como um aguilhão a perscrutar as inviabilidades do presente, foi rejeitado como método, e em seu lugar é um positivismo capengando nas muletas do neoliberalismo que serve para justificar o hoje e o amanhã. $O$ argumento de que $O$ socialismo não está presente nas atuais lutas sociais é, pois, perfeitamente inadequado: ele revela não apenas um desconhecimento do rol dos paradigmas na criação intelectual, mas sobretudo, pela aceitação da barbárie do pluralismo de ilhotas pelos intelectuais, sua des-solidarização para com o futuro das classes dominadas. 